Bangladesh J. Bot. 49(4): 1135-1140, 2020 (December)

\title{
FLOWER COLOR DIGITIZING AND PIGMENT DISTRIBUTION IN GARDEN PANSY
}

\author{
Xiaohua Du*, Miaomiao LiU, Xiaopei Zhu and Huichao LiU \\ School of Horticulture and Landscape Architecture, Henan Institute of Science \\ and Technology, Xinxiang 453003, China
}

Keywords: Pansy, Flower color, Digitizing, Pigment distribution

\begin{abstract}
The garden pansy (Viola $\times$ wittrockiana) is a large hybrid flower and most popular for its abundant flower colors. The flower colors of 12 pansy accessions were measured by using colorimeter and the pigments distribution within their petal cells were investigated. The result indicated a vast majority of the visual color of flower was consistent with the result surveyed by colorimeter in pansy. The pigments were mainly distributed in the upper and dorsal epidermal cells and most of them show the similar colors to those measured using colorimeter. The red pigment was found to be distributed in the visual blue petals and yellowish brown or khaki pigment in visual white petals. The results suggested the flower color of pansy can be objectively and accurately measured with colorimeter, and investigating pigment color and distribution in petals can help understanding pansy flower color better.
\end{abstract}

\section{Introduction}

Flower color is one of the important characteristics of ornamentals and the most eye-catching quality determinant. Creating new colors and color patterns has always been an important goal for breeders. With the efforts of ornamental breeders, a growing number of flower colors were bred, and more analogous flower colors also appeared. Due to individual differences in color perception, the description of flower color, especially analogous colors, is difficult and subjective, which hinders academic exchange and research conduct. Recently a more accurate and objective method was introduced into flower color survey. It is colorimeter that can evaluate and determine color from a multidimensional view. It compensates the human visual flaws and offers a more reliable and practical way (Voss 1992).

Pansy is one of the most colorful flowers around the world, success of artificial hybridization among intra- and interspecific by many breeders since the 19th century (Yoshioka et al. 2006, Li et al. 2014, Du et al. 2018). However, little information about pansy flower color measured by colorimeter has been reported until now. Previous workers showed that flower color is mainly determined by pigment types and their distribution (Zhao and Tao 2015, Morita and Hoshino 2018). It was verified that flavonoids are the main pigments accounted for flower color in pansy (Endo 1959, Hase et al. 1990). However, little is known about the distribution of pigment in pansy petals and their influence on flower colors. In present study for surveying the flower colors of 12 pansy accessions colorimeter was used and their distribution by microscope was investigated.

\section{Materials and Methods}

Twelve pansy (Viola $\times$ wittrockiana) accessions covering six flower colors and their analogous colors visually were employed (Table 1). The plants of these pansy accessions were grown in the horticultural farm of Henan Institute of Science and Technology (Latitude: 35.18N; Longitute: $113.55^{\circ}$ E), Xinxiang, Henan Province, China from Sept. 30, 2014 to May 30, 2015. Flower petals at full bloom were sampled and their colors except of blotch were measured by

*Author for correspondence: <duxiaohua0124@sina.com>. 
Table 1. The flower characteristics of $\mathbf{1 2}$ pansy accessions.

\begin{tabular}{llll}
\hline Accessions & Flower colors & Blotch, strip or center & Flower types \\
\hline G11-6-1 & Dark red & Black bloth, yellow center & Large \\
G11-5-1 & Violet black & Brown, yellow center & Small \\
G11-1 & Dark purple & Yellow center & Medium \\
XXL-YB-1 & Yellow & Brown blotch & Large \\
EYO-X-1 & Yellow & Stripe & Small \\
JY1 & Pure yellow & No blotches or stripe & Medium \\
JB & Bluish purple & Stripe, yellow center & Small \\
E01 & Dark purple & Stripe, yellow center & $"$ \\
SRFY & Purple & Black blotch, yellow center & Medium \\
PXP-BT-D & Bluish purple & Stripe, yellow center & $"$ \\
EWO-1 & White & Yellow center & $"$ \\
HMB-X-1 & Off-white & Purple stripes, yellow center & $"$ \\
\hline
\end{tabular}

CR-13 colorimeter (Konica Minolta, Japan) to obtain the $L^{*}, a^{*}$ and $b^{*}$ values with four biological repeats. Then Chroma $\left(C^{*}\right)$ and hue angle $\left(h^{\circ}\right)$ were calculated according to Onozaki et al. (1999),

$$
\begin{aligned}
& C^{*}=\left(a^{* 2}+b^{* 2}\right)^{1 / 2} \\
& h^{\circ}=\arctan \left(b^{*} / a^{*}\right)
\end{aligned}
$$

To clarify the pigment distribution, the upper and dorsal epidermis of petal were dissected and observed under a light microscope (Eclipse Ci-S, Nikon, Japan). The comparison of color character values including $L^{*}, a^{*}, b^{*}, C^{*}$ and $h^{\circ}$ among accessions was completed using one-way ANOVA and Tukey's post hoc tests on DPS7.55 software.

\section{Results and Discussion}

The flower colors of 12 pansy accessions were surveyed by colorimeter to obtain their $L^{*}, a^{*}$ and $b^{*}$ values. According to the color solid based on CIELAB established by International Commission on Illumination, using $L^{*}, a^{*}$ and $b^{*}$ values, each color can be assigned to a digital three-dimensional coordinate system, in which $L^{*}$ - value indicates light intensity varying from dark (0) to white (100), $a^{*}$ - value from negative to positive indicates green decline and red enhancement, and $b^{*}$ - value from negative to positive means blue decline and yellow enhancement. The $C^{*}$ value represents color saturation. The $h^{\circ}$ value increased from $0^{\circ}$ to $90^{\circ}$ indicate color shift from red-purple to yellow, while from $90^{\circ}$ to $180^{\circ}$ means yellow to bluishgreen, and $180^{\circ}$ and $270^{\circ}$ indicating from bluish-green to blue. According to the $C^{*}$ value and $h^{\circ}$ value of each accession, twelve pansy accessions were assorted into four groups (Table 2) including red (G11-6-1, G11-5-1, G11-1 and E01), yellow (XXL-YB, EYO and JY1), purple (JB, SRFY and PXP-BT-D) and white group (EWO-1 and HMB-X-1). Within the red group, G11-6-1 had a high $C^{*}$ values suggesting its higher saturation of red which conformed to its visual red petals, while G11-5-1 and G11-1 with a low $C^{*}$ value indicating higher grey degree which was consistent with its visual violet black petals (Fig. 2. 1a, 2a and 3a). Compared with other red accessions, E01 with 317.3 of $h^{*}$ was a little further from the red-purple line and towards the blue which agreed with the visual appearance (Fig. 2.10a). There was little chromatic aberration among three yellow pansy accessions. Surprisingly, the visual white group was plotted between yellow 
and bluish-green range, but with the lowest color saturation. JB, SRFY and PXP-BT-D appeared blue petals visually, while the digital results with colorimeter suggested that they fell into purple range which is between blue and reddish violet (Table 2 and Fig. 1).

Table 2. Rectangular coordinates of CIELAB color space of 12 pansy accessions.

\begin{tabular}{|c|c|c|c|c|c|c|c|}
\hline \multirow[b]{2}{*}{ Hue } & \multirow[b]{2}{*}{ Accessions } & \multicolumn{2}{|c|}{$L^{* z}$} & \multirow[b]{2}{*}{$a^{* z}$} & \multirow[b]{2}{*}{$b^{* z}$} & \multirow[b]{2}{*}{$C^{* z}$} & \multirow[b]{2}{*}{$h\left(\left(^{\circ}\right)^{\mathrm{Z}}\right.$} \\
\hline & & $\begin{array}{l}\text { Adaxial } \\
\text { side }\end{array}$ & $\begin{array}{l}\text { Abaxial } \\
\text { side }\end{array}$ & & & & \\
\hline \multirow[t]{4}{*}{ Red } & G11-6-1 & $12.3 \mathrm{e}$ & $16.6 \mathrm{~h}$ & $33.8 \mathrm{a}$ & $-1.7 \mathrm{c}$ & $33.8 b$ & $357.1 \mathrm{a}$ \\
\hline & G11-5-1 & $10.3 \mathrm{e}$ & $19.6 \mathrm{f}$ & $16.4 \mathrm{~cd}$ & $-7.5 c$ & $18.1 \mathrm{c}$ & $335.2 \mathrm{ab}$ \\
\hline & G11-1 & $42.9 \mathrm{c}$ & $21.9 f$ & $8.9 \mathrm{~d}$ & $-8.5 c$ & $12.4 \mathrm{~cd}$ & $316.9 b c$ \\
\hline & E01 & $15.8 \mathrm{e}$ & $21.4 \mathrm{f}$ & $25.9 \mathrm{ab}$ & $-23.9 d$ & $35.3 b$ & $317.3 \mathrm{bc}$ \\
\hline \multirow[t]{3}{*}{ Yellow } & XXL-YB-1 & $68.7 \mathrm{~b}$ & $60.8 c$ & $11.7 \mathrm{~cd}$ & $54.0 \mathrm{a}$ & $55.4 \mathrm{a}$ & $77.4 \mathrm{f}$ \\
\hline & EYO-X-1 & $63.0 \mathrm{~b}$ & $63.1 \mathrm{bc}$ & $11.7 \mathrm{~cd}$ & $53.3 \mathrm{a}$ & $54.6 \mathrm{a}$ & $77.5 f$ \\
\hline & JY1 & $68.1 \mathrm{~b}$ & $64.7 b$ & $8.7 \mathrm{~d}$ & $62.2 \mathrm{a}$ & $62.9 \mathrm{a}$ & $81.8 \mathrm{ef}$ \\
\hline \multirow[t]{3}{*}{ Purple (Blue) } & JB & $29.3 d$ & $32.0 \mathrm{~d}$ & $19.8 \mathrm{bc}$ & $-35.6 \mathrm{~d}$ & $40.8 b$ & $229.0 \mathrm{c}$ \\
\hline & SRFY & $28.1 \mathrm{~d}$ & $25.2 \mathrm{f}$ & $19.0 \mathrm{bc}$ & $-34.4 d$ & $39.5 b$ & $298.6 \mathrm{c}$ \\
\hline & PXP-BT-D & $25.9 \mathrm{~d}$ & $28.6 \mathrm{e}$ & $17.6 \mathrm{bc}$ & $-29.9 d$ & $35.0 \mathrm{~b}$ & $300.4 \mathrm{c}$ \\
\hline \multirow[t]{2}{*}{ White } & EWO-1 & $83.2 \mathrm{a}$ & $70.4 \mathrm{a}$ & $-2.6 \mathrm{e}$ & $3.17 b c$ & $4.3 \mathrm{~d}$ & $127.7 \mathrm{~d}$ \\
\hline & HMB-X-1 & $84.8 \mathrm{a}$ & $72.0 \mathrm{a}$ & $-4.4 \mathrm{e}$ & $15.3 b$ & $15.9 \mathrm{~cd}$ & 106. 6de \\
\hline
\end{tabular}

${ }^{\mathrm{z}}$ Values sharing a common letter are not different statistically $(\mathrm{p} \leq 0.05)$ by ANOVA followed by Tukey's post hoc test.

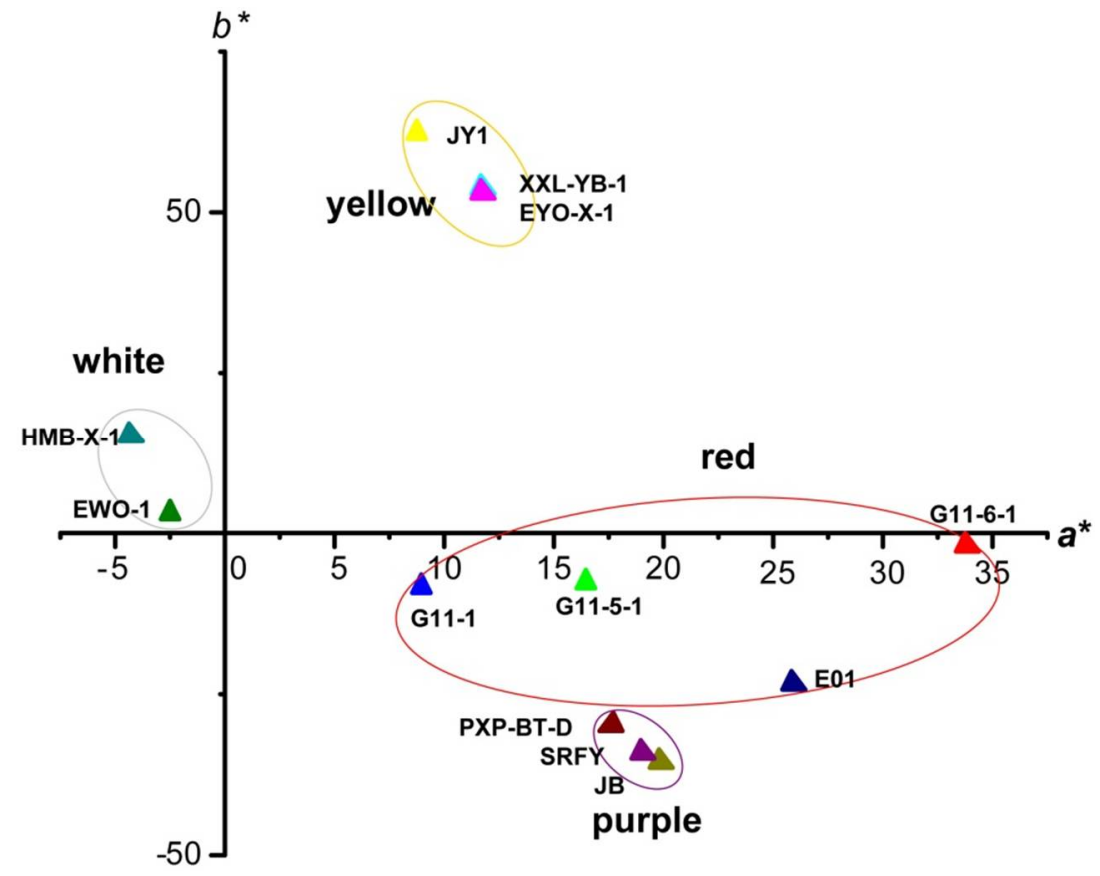

Fig. 1. Distribution of $a^{*}$ and $b^{*}$ color values of petal in 12 pansy accessions. 

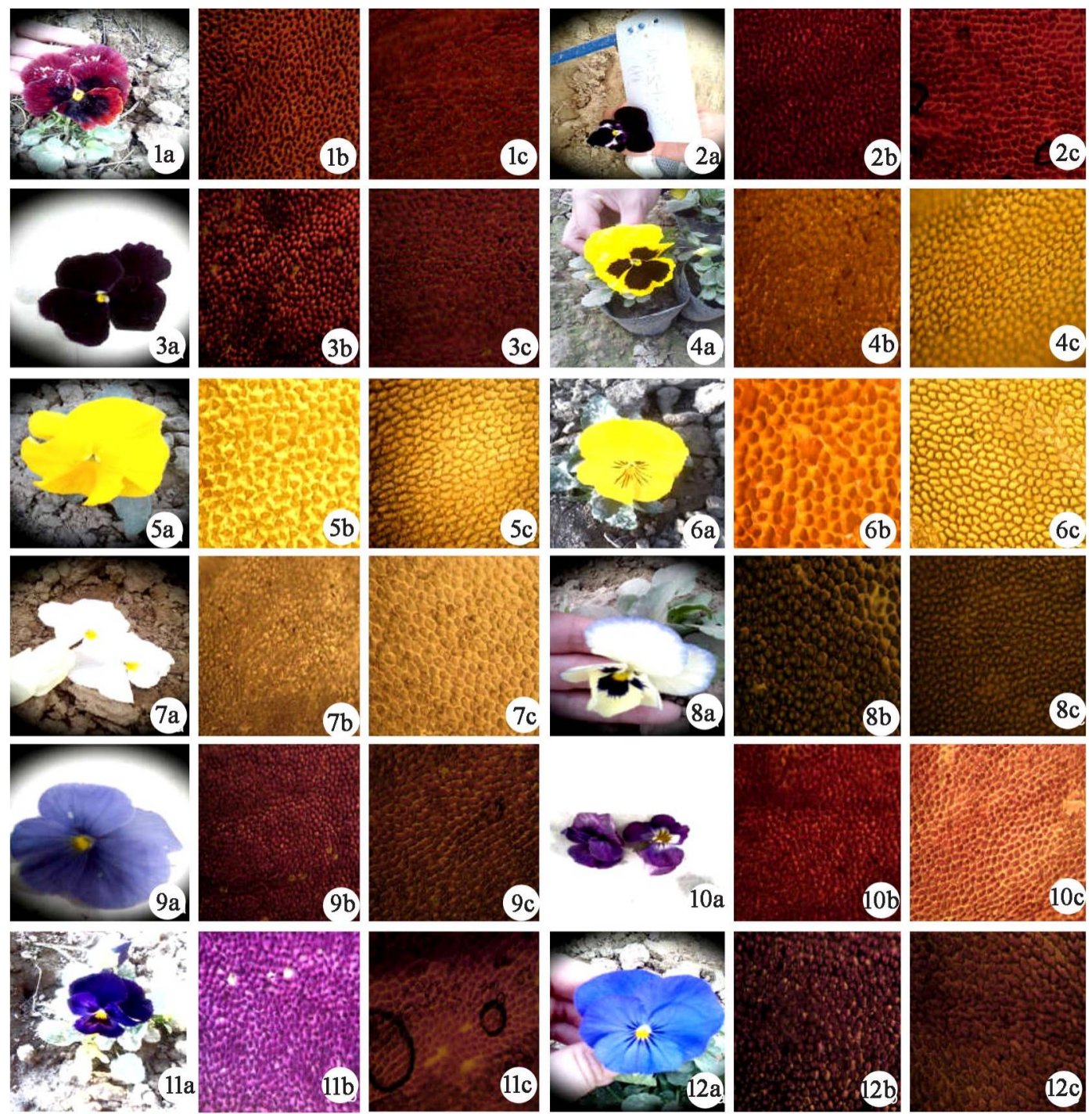

Fig. 2. The distribution of pigments from pansy petals with different colors. a. Pansy petals; $b$. The upper epidermal cell of petals; c. The dorsal epidemis cell of petals. 1. G11-6-1, 2. G11-5-1, 3. G11-1, 4.XXLYB-1, 5. JY1, 6. EYO-X-1, 7. EWO-1, 8. HMB-X-1, 9. JB, 10. E01, 11. SRFY, 12. PXP-BT-D.

Flower color is a highly complex trait. It was thought to be related to petal tissue structure (An 1989, Noda et al. 1994), pigment types (Moehs et al. 2001, Ohmiya et al. 2006, Han et al. 2014) and pigment distribution (Markham et al. 2000, Yoshida et al. 2009, Qi et al. 2013). The pigment distribution within petals of pansy was observed using microscope in the present study. The results showed the pigment mainly distributed in the upper and dorsal epidermal cells, and little pigmentation was found in the palisade and sponge tissues of pansy petals. This phenomenon was similar to that in lily (Wang 2012), but was different from that observed in Gerbera hybrida in which a large of pigment are distributed in palisade tissue besides epidermal cell (Chen et al. 2010). For the red group accessions, red or dark red pigment was observed in the upper and dorsal 
epidermal cells of G11-5-1, G11-6-1 and G11-1, once the cell layers were dissected (Fig. 2. 1a-c, $2 \mathrm{a}-\mathrm{c}$ and $3 \mathrm{a}-\mathrm{c})$, which was conformed to the results with colorimeter. Whereas E01 contained abundant red pigment in the upper but sparser dark red pigment in the dorsal epidermal cells (the data not shown). The reason for G11-5-1 and G11-1 manifesting violet black visually could be related to their higher epidermal cells density (Fig. 2.10a-c). The yellow group accessions including XXL-YB-1, EYO-X-1 and JY1 showed similar color pigmentation in their dorsal epidermal cells, but differed in their upper epidermal cells in pigmentation. JY1 was loaded with luminous yellow pigment in its upper epidermal cells while XXL-YB-1and EYO-X-1 contained orange-yellow pigment (Fig. 2. 4a-c, 5a-c and 6a-c). These differences were consistent with their plotting position in color coordinates system (Fig. 1). It was surprising to find that EWO-1 and HMB-X-1 in the white group contained khaki (Fig. 2.7a-c) and yellowish-brown (Fig. 2.8a-c) pigments in the epidermal cells, respectively. The microscopic examination further confirmed the results of colorimeter measurement (Table 2). In the purple group, purple pigment was distributed uniformly in the upper epidemic cells of petals in SRFY, red pigment in those of JB, and dark-red pigment in PXP-BT-D (Fig 2.9a-c, 11a-c and 12a-c). Purple and dark red pigment appeared in the petal epidemic cells of the purple group which was consistent with the color surveyed with colorimeter (Table 2 and Fig.1). The reason why the purple group accessions look blue could be due to the influence by petal structure which affects the light reflection or the higher $\mathrm{pH}$ in vacuole of the petal cells (Noda et al. 1994).

From the aforesaid results it is shown that color is a very complex trait. Important for the understanding of the humans eye's interpretation is that not only CIELAB quantifications are used but that also research should focus on the pigmentation of the different cell layers with a petal to get a better understanding.

\section{References}

An TQ 1989. The Mystery of Flower Color. China Forestry Press, Beijing, China.

Chen H, Liu M and Lu C 2010. Effect of pigment distribution on the color expression of Gerbera hybrida petal. Journal of Hunan Agricultural University (Natural Sciences) 36:165-168.

Du X, Wang M, Słomka A and Liu H 2018. Karyologic and heterosis studies of the artificial inter- and intraspecific hybrids of Viola $\times$ wittrockiana and Viola cornuta. Hortscience 53:1300-1305.

Endo T 1959. Biochemical and genetical investigation of flower color in Swiss giant pansy, Viola $\times$ wittrockiana Gams III: dominace relations in $\mathrm{F}_{1}$ hybrids, with special reference to flower color and anthocyanin pigment constituents. Jpn. J. Genetics 34: 116-124.

Han YJ, Wang XH, Chen WC, Dong MF, Yuan WJ, Liu X and Shang F 2014. Differential expression of carotenoid-related genes determines diversified carotenoid coloration in flower petal of Osmanthus fragrans. Tree Genet. Genomes 10: 329-338.

Hase N, Matsuura S and Yamaguchi M 1990. HPLC evaluation of anthocyanins and flavonols in relation to the flower color of pansies (Viola $\times$ wittrockiana Gams). IEEE T. on power syst. 5: 103-110.

Li Q, Wang J, Sun HY and Shang X 2014. Flower color patterning in pansy (Viola $\times$ wittrockiana Gams.) is caused by the differential expression of three genes from the anthocyanin pathway in acyanic and cyanic flower areas. Plant Physiol. Biochem. 84: 134-141.

Markham KR, Ryan KG, Gould KS and Rickards GK 2000. Cell wall sited flavonoids in lisianthus flower petals. Phytochemistry 54: 681-687.

Moehs CP, Tian L, Osteryoung KW and Dellapenna D 2001. Analysis of carotenoid biosynthetic gene expression during marigold petal development. Plant Mol. Biol. 45: 281-293.

Morita Y and Hoshino A 2018. Recent advances in flower color variation and patterning of Japanese morning glory and petunia. Breeding Sci. 68:128-138. 
Noda K, Glover BJ, Linstead P and Martin C 1994. Flower colour intensity depends on specialized cell shape controlled by a Myb-related transcription factor. Nature 369: 661-664.

Ohmiya A, Kishimoto S, Aida R, Yoshioka S and Sumitomo K 2006. Carotenoid cleavage dioxygenase (CmCCD4a) contributes to white color formation in chrysanthemum petals. Plant Physiol. 142: 11931201.

Onozaki T, Mato M, Shibata M and Ikeda H 1999. Differences in flower color and pigment composition among white carnation (Dianthus caryophyllus L.) cultivars. Scientia Horticultirae 82: 103-111.

Qi Y, Lou Q, Li H, Yue J, Liu Y and Wang Y 2013. Anatomical and biochemical studies of bicolored flower development in Muscari latifolium. Protoplasma 250: 1273-1281.

Voss D H 1992. Relating colorimeter measurement of plant color to the Royal Horticultural Society Colour Chart. HortScience 27: 1256-1260.

Wang X 2012. Evaluation of flower color and analysis of the formation of Lilium germplasm resources. Habin: Northeast Agricultural University.

Yoshida K, Miki N, Momonoi K, Kawachi M, Katou K, Okazaki Y, Uozumi N, Maesshima M and Kondo T 2009. Synchrony between flower opening and petal-color change from red to blue in morning glory, Ipomoea tricolor cv. heavenly blue. Proc. Jpn. Acad. Ser. B. 85: 187-197.

Yoshioka Y, Iwata H, Hase N, Matsuura S, Ohsawa R and Ninomiya S 2006. Genetic combining ability of petal shape in garden pansy (Viola $\times$ wittrockiana Gams) based on image analysis. Euphytica 151: 311319.

Zhao D and Tao J 2015. Recent advances on the development and regulation of flower color in ornamental plants. Front. Plant Sci. 6: 261.

(Manuscript received on 13 December, 2019; Revised on 11 May, 2020) 